\title{
SECURE INTEGRATION OF IOT AND CLOUD COMPUTING
}

\author{
Dr.Kashif Qureshi \\ SOEIT, Sanskriti University, Mathura, Uttar Pradesh, India
}

\begin{tabular}{|c|c|c|c|}
\hline Journal & \multicolumn{3}{|c|}{$\begin{array}{l}\text { Samvakti Journal of Research in Information Technology } \\
\text { https://www.sjirit.samvaktijournals.com } \\
\text { Volume } 2 \text { Year of Volume } 2021 \text { Page No : } 1 \text { - } 7\end{array}$} \\
\hline Discipline & \multicolumn{3}{|l|}{ Internet of Things } \\
\hline Conference & \multicolumn{3}{|c|}{$\begin{array}{l}\text { A virtual international conference on redefining and transforming the role of higher } \\
\text { education in sustainable development }\end{array}$} \\
\hline Conference & \multicolumn{3}{|c|}{ Start Date: September 30, 2021} \\
\hline Dates & \multicolumn{3}{|c|}{ End Date : September 30, 2021} \\
\hline Institute Name & \multicolumn{3}{|c|}{$\begin{array}{l}\text { JAIN (Deemed-to-be University) in association with Council for Industrial } \\
\text { Innovation and Research }\end{array}$} \\
\hline $\begin{array}{l}\text { Date Received } \\
\text { ID } \\
\text { Dol No. }\end{array}$ & $\begin{array}{l}\text { November } 19,2021 \\
: 2021.02 .10 \\
: 10.46402 / 2021.02 .10\end{array}$ & $\begin{array}{l}\text { Publication Date } \\
\text { Paper Type } \\
\text { Dol Url }\end{array}$ & $\begin{array}{l}\text { : December 10, } 2021 \\
\text { : Conference Paper } \\
\text { : https://dx.doi.org/10.46402/2021.02.10 }\end{array}$ \\
\hline
\end{tabular}

\section{ABSTRACT}

Mobility Technique Is a fairly latest invention that relates to an information storage and processing architecture that is separate from the wireless phone. The loT is a brandnew concept. The Internet of Things (IoT) is a comparatively recent networking technologies that is increasing popularity swiftly. IoT is more particularly linked to wireless telecommunications. The primary aim of wireless network-based interaction and collaboration amongst things and objects is to achieve the goal established for them as a united entity. Additionally, both Digital Storage and the lot are quickly evolving cellular networking capabilities. This article provides a summary of the Internet of Things (loT) and Data Storage, with an emphasis on the security concerns that both technologies face. We purposefully mix the 2 acquired notifications to look for commonalities and see what advantages there are in integrating them. Finally, we will discuss Cloud Computing's contribution to loT technologies. As a result, it demonstrates how Cloud Computing technology enhances loT functionality. Finally, we look at the security issues that come with combining loT with Cloud Computing.

KEYWORDS: Cloud Computing, Data, Device, loT, Technology. 


\section{INTRODUCTION}

The Internet of Things is a relatively recent networking technologies. The Internet of Things (loT) is a "system of connected products, appliances, automobiles, skyscrapers, and other items that are connected with technology, algorithms, sensing, and a proxy server, enabling these products to gather and share data," according to Wikipedia. The loT technology is the next huge thing in the modern technological sector, but it also means major adjustments in how businesses operate. In the next years, an increase in the amount of connected gadgets and places, as well as the jobs they will accomplish, is expected ${ }^{[1]}$.

Furthermore, the loT concept's primary strength is the significant effect it will have on a variety of elements of prospective consumers' daily lives and behavior. As a private user, the most apparent impacts of the Internet of Things would be seen in both home and professional settings. For starters, designed with different, e-health, assisted life, and better education are some examples of prospective various uses where the novel approach, the Internet of Things, will perform a significant role in this regard. Business customers in the second instance may see similar effects in fields like as transportation, bright human and cargo mobility, automated and industrialization, and marketing ${ }^{[2][3][4]}$.

The loT is divided into three sections:

- Things

- The networks of communication that link them.

- Data streaming from and to objects is used by computer systems.

As a consequence, virtualized mass storing and large computations are frequently expensive. Just a few examples include memory, communications capabilities, power, and computing restrictions. Mobile Cloud Computation is the latest technique that integrates multiple techniques to boost existing network capability and availability. In addition, some other innovation known as Mobile Cloud Computing (MCC) has enhanced in latest decades of the rise of a new creation of offerings founded on the principle of "cloud computing," that either aims to do is focus on providing direct exposure to statistics from anybody at any time by reducing or trying to eliminate necessity gadgets. Mobile computing, more exactly, is defined as the use of clouds technology in conjunction with portable apps to increase the intellectual capability, capacity, storing, fuel, and context understanding of portable electronics. A fresh strategy to digital marketing products for corporations and organisations may also be termed as mobile environment ${ }^{[5] 6][7]}$. Virtualisation is the product of multidisciplinary methodologies that incorporate touchscreens with cloud technology. Connection and ad-hoc portable clouds are both referred to as "mobile cloud." While offering capabilities to phone users, the developed system of a connectivity mobile environment remains static. Because of how Cloud Computing works, it might be used 
as a basis for Internet of Things and Monitoring Footage techniques, thereby boosting existing capabilities.

The rest of the article is organized as following. A summary of important work on "internet of things" Cognitive technology, as well as potential interaction. The Internet of Things' architecture, and also several of the most basic functions.

The benefits and benefits of combining loT technologies with Cloud Computing technology. Many studies have been conducted on the interaction of the loT devices with Cloud Services. Using cloud technology skills, a new system for offering and sustaining broadband access and real-time software activities for intelligent building needs. In moreover, it demonstrates a foundation for managing, analyzing, and controlling information obtained from large scalable, diverse, permission less, genuine and digital equipment that can be handled, examined, and typically conducted by dispersed cloud-based offerings. Examine the high tech for merging Cloud Computing with the loT systems, as well as a Technology home automation scenarios to assess IoT acceptance criteria.

Finally, the County Everything architectural was introduced, which is a Virtualized loT device infrastructure that incorporates Clouds Everything laaS, PaaS, and SaaS for accelerating Future loT generation and management. Also included is a demonstration and analysis of a few of the loT and Cloud Technology connectivity concerns that must be solved in order for a city infrastructure to handle obstacles like high energy costs, high $\mathrm{CO} 2$ output, increased commute times, and enhanced driver protection.

The strategy focuses on four areas:

- Embedding intelligence into sensors and actuators using the Arduino platform

- Networking smart things using Zigbee technology.

- Facilitating interactions with smart things using Cloud services.

- Improving data exchange efficiency using the JSON data format.

It also demonstrates the approach's feasibility and profitability by demonstrating the deployment of 3 usage, including analyzing building characteristics, controlling kitchen machines, and managing home entrance. For worldwide Internet of Things implementation, the company provides a cloud-centric strategy. First most significant development models and possible applications that will probably fuel loT study in the near term are discussed, as well as a Hybrid approach based on the interaction of cloud resources utilizing Aneka. Ultimately, it emphasizes the need of putting WSN, the online world, and cloud technology combined for the advantage of the scientific academic researchers to conclude the loT concept. As well as the volume of data that IoT devices might create and the need for digital machine usage and disk space. Integration with virtualization has become extra and more essential, also to render it conceivable to form more usability from data collected produced by loT's and grow smart solutions for the customer, but also to start making it conceivable to start creating more effectiveness from data produced by loT's and create software solutions 
for the user, a correlation known as Cloud of Things. With loT's, everything can become a corner of the Network and provide data. In addition, in order to develop more valuable solutions, the data generated should be processed in accordance with its specifications. Integration of loT's with cloud computing is becoming more essential for the preceding aim. The Cloud of Things (CoTs) is the name given to this new paradigm, which is described in. Such publications, is from the alternative side, do not examine the new CloudloT paradigms in depth, that involves whole new programs, challenges, and academic issues. The study concentrates on certain key issues in CoT and suggests a remedy concept of sophisticated major hub networking. Sensing and small loT's can't do the advanced operations and which was before that intelligent gates can. Lastly, this section covers interaction technologies such as public internet, computing topologies, and Point processing. Numerous integrating concepts and data science methodologies, as well as numerous obstacles and unsolved scientific literature, are also covered.

\section{Things Internet:}

\section{a. Internet of Things: Data Advantages:}

- Smart solution in the transportation bucket: Smart solutions in the transportation bucket decrease traffic on the roads, cut fuel consumption, prioritize car maintenance programs, and save lives.

- Smart power grids with more renewables: Smart power grids with more renewables enhance system dependability while lowering customer costs, resulting in cheaper energy.

- Patient monitoring through remote access: Patient monitoring by remote access enhances the quality of services, increases the number of individuals serviced, and saves money.

- Sensors in houses and airports: Sensors in homes and airports, as well as in your shoes and doors, enhance safety by transmitting signals when they are left unattended for a length of time or when they are utilized at the incorrect time.

\section{b. Internet of Things (IoT) Security:}

The safety of connected computers and systems in the Web of Things is the subject of Information phones. The Concept that relates to the expanding amount of goods and organizations - referred to as objects in this context - that are endowed with special Characters and the ability to send information over a system independently. Processor architectures, intelligent sensing networks used in commercial machine-tomachine (M2M) networking, smart electricity networks, house and buildings management, vehicle-to-vehicle interaction, and wearable's technology gadgets all contribute to Networking network expansion.

The main problem is that, considering networked gadgets and other goods are still a novel idea, cybersecurity has not consistently been considered in product development. Heterogeneous distributed platforms and applications are frequently 
included with loT gadgets that are old of current and unsecure. Additionally, consumers sometimes forget to update the login credentials protection on connected devices, or even when they do, they do not select usernames that are sufficiently strong. To improve protection, an Electronic system that must be physically available on the Web should have been separated out of its own overall networking accessibility should indeed be restricted. The development stems from social should also be monitored for any unusual traffic, and if one is detected, appropriate action needs to be made.

\section{Cloud Computing:}

That the utilization of Web to provide machines, data, companies, and programs is known as cloud computing. To make cellphones increasingly power economical and intellectually capable, considerable technological and programming advances are required. Researchers and manufactures must work together to achieve this.

The combination of internet services with portable apps in particular to optimize the processor, capacity, space, battery, and sensing capabilities of the smart phones is referred to as mobility cloud technology. Interdisciplinary methodologies that integrate portable computer with cloud services have resulted in portable clouds computer technologies. As a consequence, another term for this multidisciplinary field is portable software as a service.

The term "mobile cloud" may be interpreted in two ways: connectivity portable clouds and ad-hoc mobile cloud. While offering capabilities to phone devices, the embedded system of a connection cloud server remains fixed. Despite this, many programs employ public cloud for storing and implementation functionality, such as Apple's Siri (voice-activated personal assistant) and iCloud centralized repository.

\section{Integration of IoT and Cloud Computing:}

In addition, a young crop of applications oriented by the concept of "cloud computing" has evolved in latter decades, with the objective of providing accessibility from any place at any time, while lowering or eradicating the need for hardware resources. "Cloud computation" refers with the use of computational administrative capabilities, as well as programming, via the utilization of companies offered over the Web. Cloud applications are quickly and 1 of the more aggressive industries in the globe for IT and development companies. Public cloud is a kind of technologies that may be utilized to build loT solutions.

Portable Public Clouds, in specifically, is defined as the combination of cloud - based services with portable apps to increase the computational capacity, storage, store, electricity, and spatial intelligence of handheld phones. Mobile Cloud Computing is the product of scientific methodologies that combine mobile applications with virtualization. Users may also acquire machines, memory, companies, and tools through the Interties via cloud storage. 


\section{DIscussion}

The author has explored the safe incorporation of loT and Cloud Computing. Cloud computing technologies has numerous benefits, but it also has significant disadvantages. Cloud services is kind of an equipment that allows data to be stored and processed in anything other than a mobile app. We provide an introduction of loT innovation in this post, but also an explanations of how it operates and what to use it. We also go through the major features of Cloud Computing as well as the trade-offs which comes with it. Cloud technology is some kind of architecture that stores and processes information except in a smart phone. Furthermore, the Internet is a mature technologies that is rapidly acquiring popularity in the telecoms business, notably in the field of cellular telephony today.

The basic purpose of wireless internet contacts and cooperation amongst entities and devices is to help them reach a common goal. In addition, Cloud Services and the Cellular sensor Networks are also rapidly evolving capabilities that rely on Bluetooth connectivity.

\section{CONCLUSION}

After concluding on the safe connection of IoT and Cloud Computing, the author emphasized the importance of Cloud Applications in loT innovation, as well as how Cloud Innovation promotes loT capability. Furthermore, the proposed approach framework was utilized to examine the privacy challenges of loT and Cloud Computing integrating, and thus a description of how and why the two encrypting techniques used contributed to IoT and Cloud Computing assimilation. This region may be the subject of ongoing research into the merging of those different systems. Due to the rapidly growing of the both platforms, the safety issue must be resolved or substantially decreased in order to create a good analysis framework. This study's cybersecurity problems might be utilized as a case study. The purpose studies with the goal of minimizing those. 


\section{REFERENCES}

[1] I. A. T. Hashem, I. Yaqoob, N. B. Anuar, S. Mokhtar, A. Gani, and S. Ullah Khan, "The rise of 'big data' on cloud computing: Review and open research issues," Information Systems. 2015, doi: 10.1016/j.is.2014.07.006.

[2] V. Pushpalatha, K. B. Sudeepa, and H. N. Mahendra, "A survey on security issues in cloud computing," Int. J. Eng. Technol., 2018, doi: 10.23956/ijarcsse/sv7i5/0217.

[3] K. Akherfi, M. Gerndt, and H. Harroud, "Mobile cloud computing for computation offloading: Issues and challenges," Applied Computing and Informatics. 2018, doi: 10.1016/j.aci.2016.11.002.

[4] C. Stergiou, K. E. Psannis, B. G. Kim, and B. Gupta, "Secure integration of loT and Cloud Computing," Futur. Gener. Comput. Syst., 2018, doi: 10.1016/j.future.2016.11.031.

[5] B. de Bruin and L. Floridi, "The Ethics of Cloud Computing," Sci. Eng. Ethics, 2017, doi: 10.1007/s11948-016-9759-0.

[6] Q. Zhang, L. Cheng, and R. Boutaba, "Cloud computing: State-of-the-art and research challenges," J. Internet Serv. Appl., 2010, doi: 10.1007/s13174-0100007-6.

[7] S. Shilpashree, R. R. Patil, and C. Parvathi, "Cloud computing an overview," Int. J. Eng. Technol., 2018, doi: 10.14419/ijet.v7i4.10904.

\section{$\underline{\underline{E N D}}$}

